\title{
Cysteine-Rich Intestinal Protein 1 Silencing Inhibits Migration and Invasion in Human Colorectal Cancer
}

\author{
Guoyang Hea, biyuan Zou ${ }^{\mathrm{a}}$ Lin Zhou ${ }^{\mathrm{d}}$ Peiqiong Gao ${ }^{\mathrm{a}} \quad$ Xinlai Qian ${ }^{\mathrm{a}} \quad$ Jing Cui \\ aDepartment of Pathology, Xinxiang Medical University, Xinxiang, bGuangdong Provincial Key \\ Laboratory of Molecular Oncologic Pathology, Southern Medical University, Guangzhou, 'Prevention \\ and Health Care Department, The Third Affiliated Hospital, Sun Yat-sen University, Guangzhou; dFirst \\ School of Clinical Medicine, Southern Medical University, Guangzhou, China
}

\section{Key Words}

Cysteine-rich intestinal protein 1 - SW620 - HT29 - Oncogenic role • Colorectal cancer • Metastasis

\begin{abstract}
Background/Aims: Cysteine-rich intestinal protein 1 (CRIP1), a member of the LIM/double zinc finger protein family, is abnormally expressed in several tumour types. However, few data are available on the role of CRIP1 in cancer. In the present study, we aimed to investigate the expression profile and functions of CRIP1 in colorectal cancer. Methods: To examine the protein expression level of CRIP1, immunohistochemistry (IHC) was performed on 56 pairs of colon cancer tissue samples. Western blotting was performed to investigate CRIP1 protein expression in four colon cancer cell lines. The endogenous expression of CRIP1 was suppressed using short interfering RNAs (siRNAs). Cell proliferation assays were used to determine whether CRIP1 silencing affected cell proliferation. Flow cytometry analysis was used to detect cell apoptosis. The effects of silencing CRIPI on cell migration and invasion was detected using the transwell and wound-healing assays. Results: IHC analysis showed that protein level of CRIP1 was significantly higher in tumour tissue samples than in paired nontumour tissue samples and that the CRIP1 level was higher in metastatic tissue samples than in non-metastatic tissue samples. In addition, protein levels of CRIP1 were higher in highly metastatic colon cancer cell lines than in colon cancer cell lines with low metastasis. Further, CRIP1 silencing had no effect on cell proliferation or apoptosis in SW620 and HT29 cells. CRIP1 silencing suppressed cell migration and invasion obviously in SW620 and HT29 cells. Conclusion: The present study provides new evidence that abnormal expression of CRIP1 might be related to the degree of metastasis in colorectal cancer and that CRIPI silencing could effectively inhibit migration and invasion during colorectal cancer development. These findings might aid the development of a biomarker for colon cancer prognosis and metastasis, and thus help to treat this common type of cancer.

G. He and L. Zou contributed equally to this work.

Xinlai Qian

and Jing Cui

Department of Pathology, Xinxiang Medical University, 601, Jinsui Street, Xinxiang 453000, Henan (China)

Tel. +86-0373-3029160, E-Mail xxmusfyblkqxl@126.com/xxmusfyblkcj@126.com
\end{abstract}

\section{KARGER}




\section{Introduction}

Colorectal cancer (CRC), also known as bowel cancer and colon cancer, represents the development of tumours in the colon or rectum. CRC is the second most commonly diagnosed cancer in females and the third in males, with an estimated 693, 900 deaths and 1.4 million cases occurring in 2012 [1]. CRC is the fourth most common cause of cancer death after lung, stomach, and liver cancer, greatly threatening human life and health. Although the morbidity and mortality rates have declined in some western countries, they have remained high in China and other developing countries [2-4]. The main reason that rates have remained elevated in some countries is the invasion and metastasis of the tumour, leading to recurrence, which ultimately results in death [5]. Invasion and metastasis are complex processes, with multistage, multi-gene involvement and multi-factor accumulation; therefore, the study of the molecular mechanisms underlying the invasion and metastasis of CRC might help to improve the treatment and prognosis of patients with CRC.

Cysteine-rich intestinal protein 1 (CRIP1) belongs to the LIM/double zinc finger protein family. CRIP1 is abnormally expressed in several tumour types, including osteosarcoma, breast, cervical, and prostate cancers [5-10]. In breast cancer tissue, CRIP1 expression is significantly associated with a worse prognosis and has been identified as an ideal biomarker for the staging of breast cancer [8]. However, in osteosarcoma and gastric cancer, CRIP1 expression is associated with better long-term survival and the absence of metastases, indicating a favourable prognostic effect $[6,11]$. The function of CRIP1 has been studied in vitro, using breast cancer cells. CRIP1 knockdown increased cell proliferation and cell invasion in the T47D and BT474 breast cancer cell lines [8]. In addition, downregulation of CRIP1 mRNA has been demonstrated in invasive pancreatic carcinoma using cDNA microarray analysis [12]. To date, study of CRIP1 is limited, and comprehensive data are not available. More studies are needed to determine whether CRIP1 can be used as a biomarker for malignant tumours, especially for the invasion and metastasis of cancer.

CRIP1 was found to be overexpressed in the highly metastatic colon cancer cell line E1, compared to the parental HCT-116 epithelial-like colon cells [13]. E1 cells display features characteristic of the epithelial-mesenchymal transition, and possess increased motility and invasiveness compared to parental HCT-116 cells. We hypothesised that CRIP1 might play a role in regulating the invasion and metastasis of CRC; therefore, in the present study we aimed to investigate the expression profile and functions of CRIP1 in CRC. The results revealed that abnormal expression of CRIP1 might be related to the degree of CRC metastasis and that CRIP1 silencing could effectively inhibit migration and invasion during CRC development. These findings might aid the development of a biomarker for colon cancer prognosis and metastasis, and thus help treat this common type of cancer.

\section{Materials and Methods}

\section{Patients and tissue samples}

Colon cancer tissue samples were obtained from 56 patients who underwent surgical resection in the Department of Pathology, Xinxiang Medical University. None of the patients had received chemotherapy and/or other therapies before the surgical procedure. Table 1 presents the clinicopathological data for the 56 patients. All patients were staged according to the American Joint Committee on Cancer (AJCC) tumour, necrosis, metastasis (TNM) staging system for colon cancer (Seventh Edition). The study protocol was approved by the Ethics Committee of Xinxiang Medical University. All 56 patients provided written informed consent for their tissues to be used in this study.

Immunohistochemistry (IHC)

Paraffin-embedded specimens were cut into $4-\mu \mathrm{m}$ sections and heated at $60{ }^{\circ} \mathrm{C}$ for $60 \mathrm{~min}$. The sections were deparaffinised with xylene and rehydrated. The sections were then submerged in Ethylenediaminetetraacetic acid (EDTA) antigenic retrieval buffer in a pressure cooker for 5 min and then 


\section{Cellular Physiology Cell Physiol Biochem 2017;44:897-906 \begin{tabular}{l|l|l} 
and BOI: 10.1159/000485357 & $\begin{array}{l}\text { C } 2017 \text { The Author(s). Published by S. Karger AG, Basel } \\
\text { www.karger.com/cpb }\end{array}$
\end{tabular} \\ He et al.: The Function of CRIP1 in Colorectal Cancer}

Table 1. Correlations between cysteine-rich intestinal protein 1 (CRIP1) protein expression and clinicopathological factors of patients with colorectal cancer. TNM, tumour, node and metastasis

\begin{tabular}{lcccc}
\hline Characteristic & Patients (n) & $\begin{array}{c}\text { CRIP1 } \\
\text { expression } \\
\text { High } \\
\text { (n = 40) }\end{array}$ & $\begin{array}{c}\text { Low } \\
\text { (n= } \\
16)\end{array}$ & P-value \\
\hline Age & 18 & 14 & 4 & 0.469 \\
$<60$ & 38 & 26 & 12 & 0.166 \\
$\geq 60$ & 34 & 22 & 12 & \\
Gender & 22 & 18 & 4 & 0.239 \\
Male & 18 & 11 & 7 & \\
Female & 38 & 29 & 9 & 0.007 \\
Tumour diameter & & & & \\
$<5$ cm & 26 & 14 & 12 & 0.002 \\
$\geq 5$ cm & 30 & 26 & 4 & \\
TNM stage & & & & \\
III + IV & 24 & 12 & 12 & \\
Lymphatic metastasis & 32 & 28 & 4 & \\
Negative & & & & \\
Positive & & &
\end{tabular}

cooled at $37^{\circ} \mathrm{C}$ for $30 \mathrm{~min}$. The sections were treated with $3 \%$ hydrogen peroxide in methanol to quench endogenous peroxidase activity. After incubation with goat serum, the sections were incubated with antiCRIP1 rabbit polyclonal antibodies (1:100; ab211631; Cambridge, MA, USA) overnight at $4{ }^{\circ} \mathrm{C}$. After three rounds of washing with phosphate-buffered saline (PBS), the tissue sections were incubated with biotinylated secondary antibody (Maixin Biotechnology Company, Fuzhou, China) for $1 \mathrm{~h}$ at room temperature, followed by incubation with streptavidin-horseradish peroxidase for $5 \mathrm{~min}$. After three rounds of washing with PBS, diaminobenzidine (DAB) was added for visualisation. The sections were counterstained with haematoxylin.

CRIP1 protein levels were evaluated using the immunoreactive-score (IRS) system (combining the positive cell ratio and staining intensity). An IRS score of $\geq 6$ was used to define tumours as having a high level of CRIP1, and an IRS score of $<6$ was used to indicate a low level of CRIP1 [14].

\section{Cell culture and siRNA interference}

The human colon cancer cell lines SW620, HT29, HCT116, and HCT8 were purchased from the ATCC (America Type Culture Collection, Manassas, VA, USA). All cells were grown in Roswell Park Memorial Institute (RPMI)-1640 medium with 10\% foetal bovine serum (FBS) (GIBCO/BRL, MD, USA), supplemented with $100 \mathrm{U} / \mathrm{mL}$ penicillin G and $100 \mu \mathrm{g} / \mathrm{mL}$ streptomycin (Sigma-Aldrich Corp., St. Louis, MO, USA). Cells were maintained at $37^{\circ} \mathrm{C}$ in a humidified $5 \% \mathrm{CO}_{2}$ incubator.

The siRNA oligonucleotides (CRIP1-134: 5'-GCAACAAGGAGGUGUACUUTT-3'; CRIP1-206:5'GCGAGAAAUGUGGGAAGACTT-3'; CRIP1-326: 5'-CCGAGAGCCACACUUUCAATT-3') targeting the CRIP1 gene were obtained from GenePharma (Shanghai, China). SW620 and HT29 cells were transfected with CRIP1 siRNA at $100 \mathrm{nM}$ using Lipofectamine 2000 (Promega, Madison, WI, USA). Transfection was conducted for 48 $h$. The rate of inhibition of CRIP1 expression was verified using quantitative real-time reverse transcription PCR (qRT-PCR).

\section{Quantitative real-time reverse transcription PCR}

Total RNA was extracted using the TRIzol Reagent (Promega) according to the manufacturer's protocol. One microgram of total RNA was reverse-transcribed into cDNA, using RevertAid Premium Reverse Transcriptase (MBI Fermentas). qRT-PCR was performed using THUNDERBIRD SYBR qPCR Mix (TOYOBO). The primer sequences targeting CRIP1 were as follows: 5'-CCTGCCTGAAGTGCGAGAAAT-3' and 5'-CCTTTAGGCCCAAACATGGC-3'. Gene expression was normalised using glyceraldehyde-3-phosphate dehydrogenase (GAPDH) as the internal control. PCR primer sequences targeting GAPDH were as follows: 5'-TGCACCACCAACTGCTTAGC-3' and 5'-GGCATGGACTGTGGTCATGAG-3'. Amplification was performed using the following PCR profile: preheating at $95^{\circ} \mathrm{C}$ for $5 \mathrm{~min}$, followed by 42 cycles of $95{ }^{\circ} \mathrm{C}$ for $30 \mathrm{~s}, 58{ }^{\circ} \mathrm{C}$ for $30 \mathrm{~s}$, and $72{ }^{\circ} \mathrm{C}$ for $20 \mathrm{~s}$. Gene expression was measured in triplicate, and quantified by the $2^{-\Delta \Delta \mathrm{Ct}}$ method.

\section{Cell proliferation assay}

Cell proliferation was monitored using the CellTiter $96^{\circledR}$ AQueous One Solution Cell Proliferation Assay (Promega) following the manufacturer's protocol. At $24 \mathrm{~h}$ after transfection with the CRIP1-134 siRNA or 


\section{Cellular Physiology Cell Physiol Biochem 2017;44:897-906 \begin{tabular}{l|l|l}
\hline DOI: 10.1159/000485357 & $\begin{array}{l}\text { C } 2017 \text { The Author(s). Published by S. Karger AG, Basel } \\
\text { www.karger.com/cpb }\end{array}$ \\
\hline
\end{tabular}}

He et al.: The Function of CRIP1 in Colorectal Cancer

the scrambled control (NC), SW620 and HT29 cells were seeded at $1 \times 10^{3}$ per well in 96 -well plates. The cell proliferation assay was performed at 48, 72, and $96 \mathrm{~h}$ after transfection. After adding $20 \mu \mathrm{L}$ of CellTiter $96^{\circledR} \mathrm{AQueous}$ One Solution Reagent to each well, the plate was incubated for $4 \mathrm{~h}$ at $37^{\circ} \mathrm{C}$. At each time point of incubation, absorbance was measured at $490 \mathrm{~nm}$ using a Vmax microplate spectrophotometer (Molecular Devices, Sunnyvale, CA, USA). Each sample was assayed three times.

\section{Flow cytometric analysis}

SW620 and HT29 cells were harvested $48 \mathrm{~h}$ after CRIP1-134 siRNA or NC transfection. Cells were labelled with AnnexinV for $15 \mathrm{~min}$ in the dark. Propidium iodide (PI) was added to each sample at $50 \mu \mathrm{g} /$ $\mathrm{mL}$ before the distribution of cell apoptosis was analysed. Cell apoptosis features were analysed using a BD FACSCalibur Flow Cytometer System (BD LSRII, San Jose, CA, USA). Flow cytometric analysis was performed in triplicate.

\section{Western blotting}

Total proteins were extracted from each group of cells using RIPA Lysis Buffer (Beyotime Biotechnology, Shanghai, China), following the manufacturer's protocol. Proteins $(30 \mu \mathrm{g})$ were separated by $15 \%$ SDS polyacrylamide gel electrophoresis and transferred onto polyvinylidene difluoride (PVDF) membranes (Millipore, Billerica, MA, USA). Membranes were blocked for $1 \mathrm{~h}$ at $37{ }^{\circ} \mathrm{C}$ with $5 \%$ non-fat milk and subsequently incubated with anti-CRIP1 rabbit polyclonal antibodies (1:1000; ab211631; Cambridge, MA, USA) and GAPDH (1:4000 dilution, Santa Cruz Biotechnology, Santa Cruz, CA, USA) in 5\% non-fat milk for $1 \mathrm{~h}$ at $37^{\circ} \mathrm{C}$. After washing with Tris-buffered saline (TBS) containing 0.5\% Tween 20 (TBST), membranes were incubated with horseradish peroxidase (HRP)-conjugated secondary antibody at $37{ }^{\circ} \mathrm{C}$ for $40 \mathrm{~min}$. After further washing with TBST, membranes were assayed via enhanced chemiluminescence (ECL) and recorded on X-ray films.

\section{Transwell assay}

SW620 and HT29 cells were transfected with CRIP1-134 siRNA or NC, and subsequently cultivated for 24 h. For cell migration, each group of transfected SW620 and HT29 cells was harvested, and $1 \times 10^{4}$ cells in $100 \mu \mathrm{L}$ of non-serum medium was placed in the upper chamber of an insert (pore size, $8 \mu \mathrm{m}$ ) (Becton Dickinson Labware). The lower chamber was filled with $600 \mu \mathrm{L}$ RPMI-1640 medium with 20\% FBS. For cell invasion, $1 \times 10^{4}$ cells in $100 \mu \mathrm{L}$ of non-serum medium was placed in the upper chamber, which was precoated with Matrigel (BD Biosciences). The lower chamber was filled with $600 \mu \mathrm{L}$ RPMI-1640 medium with $20 \%$ FBS. After $24 \mathrm{~h}$ of incubation, cells were removed from the upper chamber of the filter, using a cotton swab. Cells on the underside were washed with PBS and fixed with $5 \%$ glutaraldehyde, stained with $0.5 \%$ crystal violet, and counted in five randomly selected fields under a phase contrast microscope. Assays were performed in triplicate.

\section{Wound-healing assay}

An artificial wound was created $24 \mathrm{~h}$ after transfection with CRIP1-134 siRNA or NC using a 10- $\mu \mathrm{L}$ micropipette tip. The SW620 and HT29 cells were then cultured with 2\% FBS for 24 h. To visualize the migrated cells and wound healing, images were taken at 0 and $24 \mathrm{~h}$. Assays were performed in triplicate.

\section{Statistical analysis}

All results are presented as the mean \pm standard deviation, and were analysed using SPSS software, version 19.0 (IBM SPSS, Armonk, NY, USA). One-way analysis of variance was used to determine statistical significance. $P<0.05$ was considered to indicate a statistically significant difference.

\section{Results}

Protein level of CRIP1 in colon cancer tissue samples and cell lines

To examine the protein level of CRIP1, IHC was performed on 56 pairs of colon cancer tissue samples (tumour and adjacent non-tumour tissue samples). A significant increase in the CRIP1 protein level was identified in tumour tissue samples compared with paired non- 
Fig. 1. The protein expression level of cysteinerich intestinal protein 1 (CRIP1) in colon cancer tissue samples and cell lines. A: Representative image of the CRIP1 protein expression level in colon cancer tissue samples (tumour and adjacent non-tumour tissue samples) detected by immunohistochemistry. ANT: adjacent nontumour. B: Protein level of CRIP1 in two highly metastatic colon cancer cell lines (SW620 and HT29) and two low-metastasis colon cancer cell lines (HCT116 and HCT8), as assessed by western blotting.
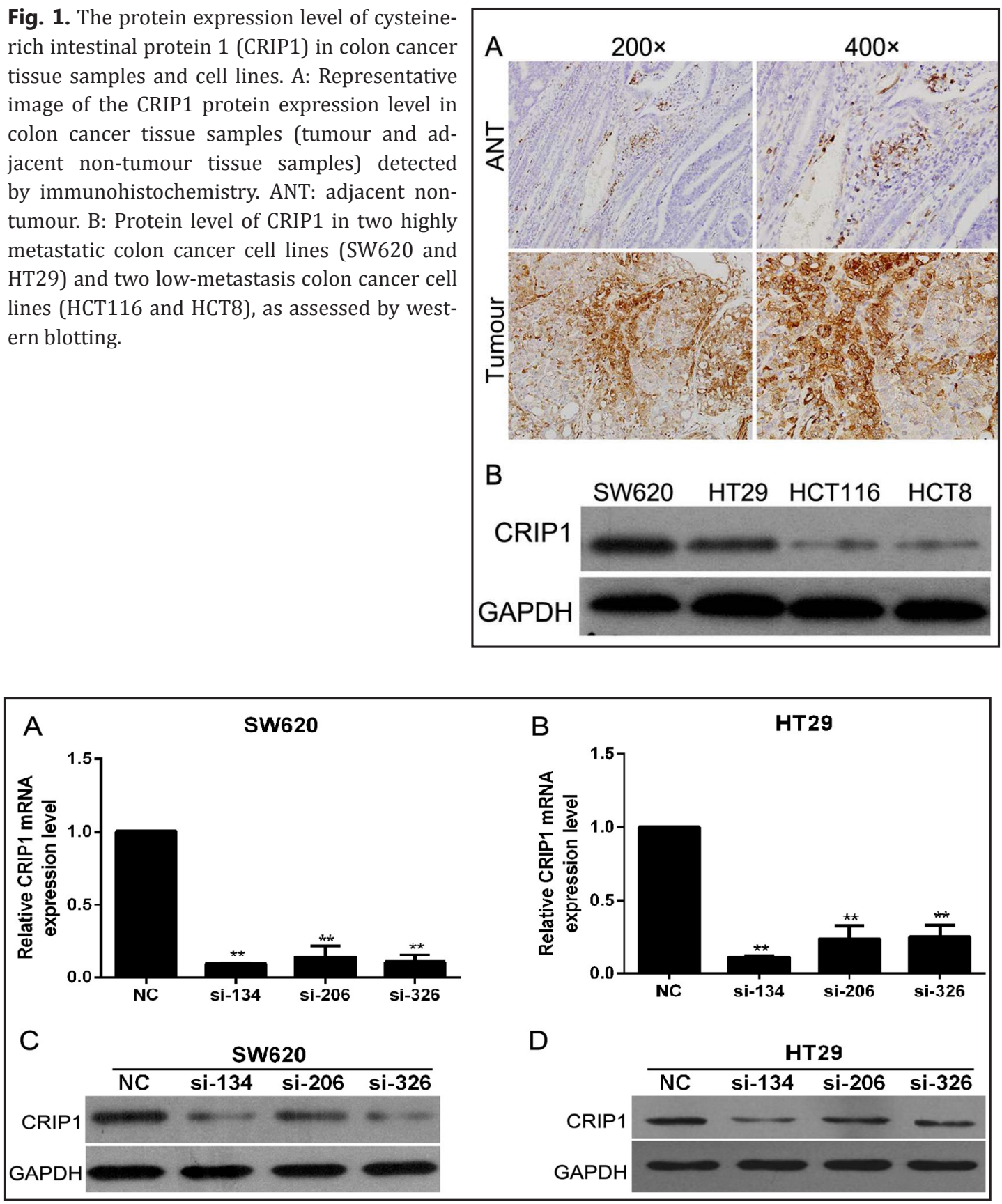

Fig. 2. Silencing efficiency of the short interfering RNA (siRNA) targeting cysteine-rich intestinal protein 1 (CRIP1) expression. SW620 and HT29 cells were transfected with the CRIP1 siRNA or a scrambled control, (NC). The endogenous expression of CRIP1 was examined by quantitative real-time reverse transcription PCR (qRT-PCR) (A and B) and western blotting (C and D). Glyceraldehyde-3-phosphate dehydrogenase (GAPDH) was used as the internal control for western blotting. Data represent mean \pm SD of at least three independent experiments. ${ }^{* *} \mathrm{p}<0.01$.

tumour tissue samples (Fig. 1A). In addition, we analysed the correlation between the level of CRIP1 and various clinicopathological parameters, and the results are summarised in Table 1. CRIP1 expression was not associated with age, gender or tumour diameter, but increased 
Fig. 3. The effect of cysteine-rich intestinal protein 1 (CRIP1) silencing on cell proliferation and apoptosis in SW620 and HT29 cells. A-B: After transfection with CRIP1 short interfering RNA (siRNA) or scrambled control (NC siRNA) for 24 , 48, and $72 \mathrm{~h}$, cell proliferation was monitored using the CellTiter 96 AQueous One Solution Cell Proliferation Assay and the $\mathrm{OD}_{490 \mathrm{~nm}}$ was measured in each group of SW620 (A) and HT29 (B) cells.
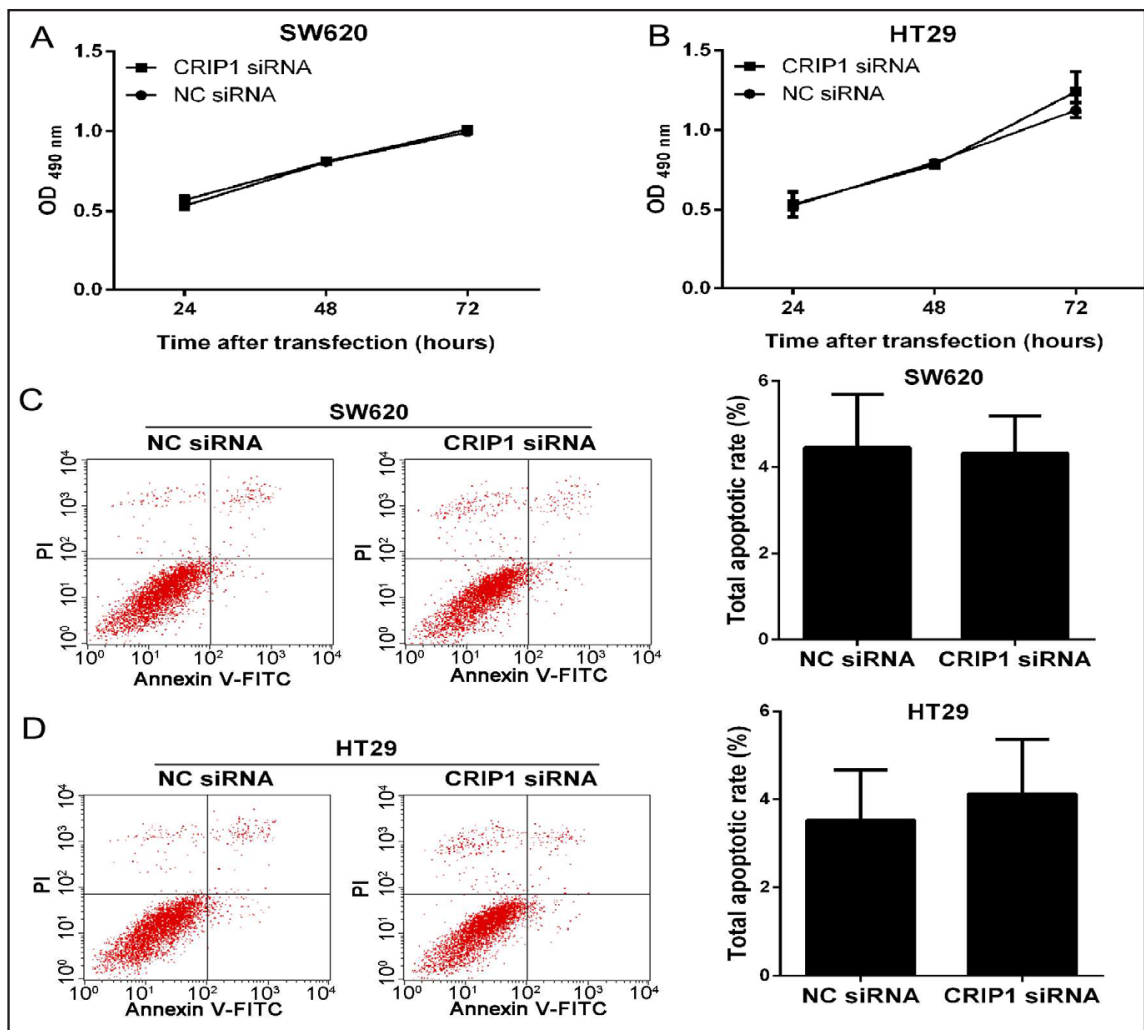

C-D: After transfec-

tion for $48 \mathrm{~h}$, the percentage of apoptotic SW620 (C) and HT29 (D) cells was detected using flow cytometry analysis. The left images show a representative graph of each group. In all four plots, viable cells are seen in the left lower quadrant (FITC/PI); early apoptotic cells in the right lower quadrant (FITC $/$ PI); late apoptotic cells in the right upper quadrant $\left(\mathrm{FITC}^{+} / \mathrm{PI}^{+}\right)$; and necrotic cells in the left upper quadrant $\left(\mathrm{FITC}^{-} / \mathrm{PI}^{+}\right)$. The right image shows the percentage of apoptotic SW620 and HT29 cells.

CRIP1 was significantly associated with TNM stage, and lymphatic metastasis (Table $1, P<$ 0.05 for each). These results indicated that an increase in CRIP1 might be associated with colon cancer aggressiveness, especially tumour invasion ability.

To further verify the protein level of CRIP1 in colon cancer, the protein level of CRIP1 was examined in two highly metastatic colon cancer cell lines (SW620 and HT29) and two colon cancer cell lines with low metastasis (HCT116 and HCT8) using western blotting. The protein level of CRIP1 was higher in the highly metastatic colon cancer cell lines than in the low-metastasis colon cancer cell lines (Fig. 1B). The CRIP1 expression level was highest in the highly metastatic colon cancer cell lines SW620 and HT29. Based on these results, we chose SW620 and HT29 as the cell lines for subsequent experiments.

The effect of CRIP1 silencing on cell proliferation and apoptosis in SW620 and HT29 cells

To attenuate CRIP1 expression, CRIP1 siRNAs were synthesised and transiently transfected into SW620 and HT29 cells, and the cells were cultured for 48 h. CRIP1 mRNA expression was successfully downregulated in SW620 and HT29 cells transfected with the CRIP1 siRNAs (si-134, si-206, and si-326) compared with those transfected with the NC siRNA (Fig. 2A and 2B). Moreover, the CRIP1 protein level was successfully downregulated in SW620 and HT29 cells transfected with CRIP1 siRNA (si-134, si-206, and si-326) compared with those transfected with the NC siRNA (Fig. 2C and 2D). Among all the CRIP1 siRNAs, si134 showed the best silencing effect, and therefore si-134, hereafter referred to as CRIP1 siRNA, was chosen for subsequent assays. 
Fig. 4. The effect of cysteinerich intestinal protein 1 (CRIP1) silencing on the cell migration ability of SW620 and HT29 cells. SW620 and HT29 cells were transfected with CRIP1 short interfering RNA (siRNA) or scrambled control (NC siRNA), and subsequently cultivated for 24 h. Then, transwell (A-B) and wound-healing assays (C-D) were performed to detect the cell migration ability of SW620 and HT29 cells. Representative graphs for each group are presented on the left. The graphs on the right show the results of analysis of five randomly selected fields. ${ }^{* *} \mathrm{P}<0.01$ compared with NC.
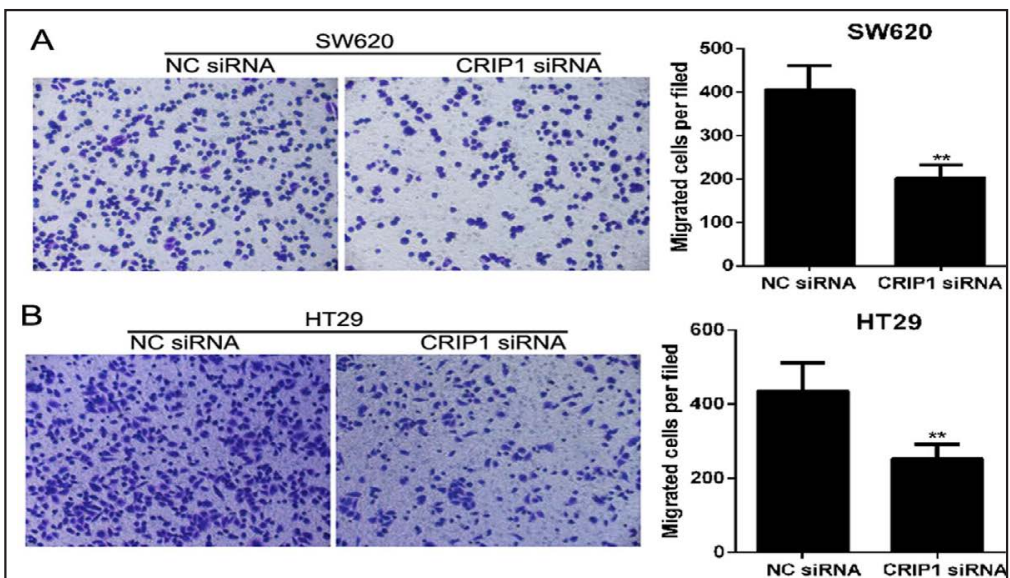

C
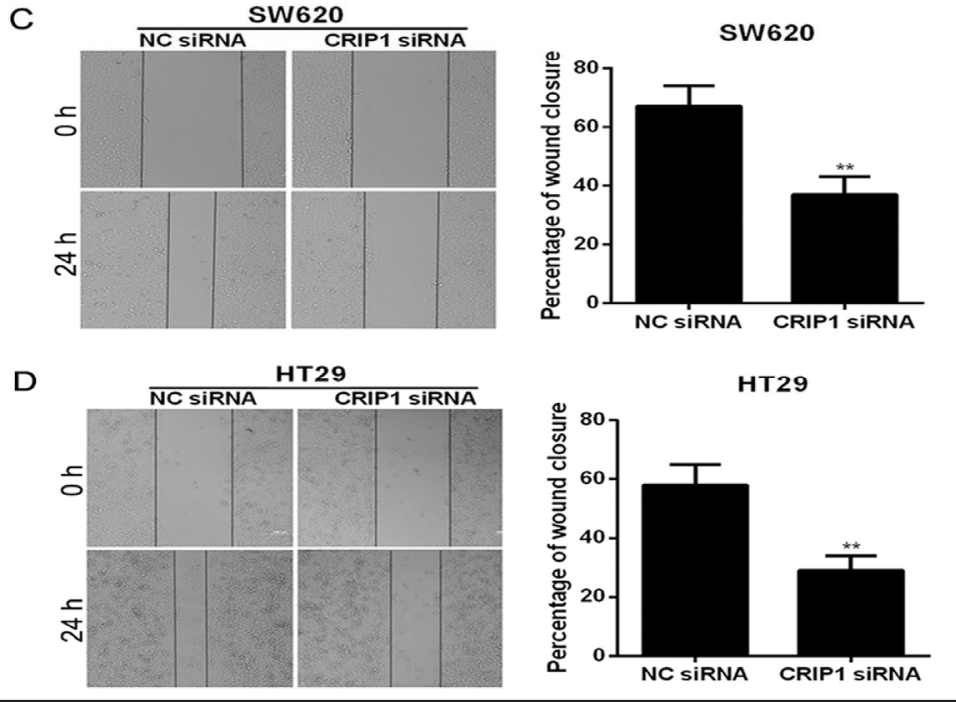

To determine whether CRIP1 silencing affects cell proliferation, a cell proliferation assay was performed in triplicate. The $\mathrm{OD}_{490 \mathrm{~nm}}$ of SW620 and HT29 cells transfected with the CRIP1 siRNA showed no obvious difference from the $\mathrm{OD}_{490 \mathrm{~nm}}$ of SW620 and HT29 cells transfected with the NC siRNA at 24, 48, and $72 \mathrm{~h}$ (Fig. 3A and 3B). These results indicated that CRIP1 silencing does not affect the proliferation of SW620 and HT29 cells.

Next, we investigated the effects of CRIP1 silencing on cell apoptosis using flow cytometry. Cell apoptosis analysis showed that CRIP1 silencing did not significantly affect the percentage of apoptotic SW620 and HT29 cells (Fig. 3C and 3D).

The effect of CRIP1 silencing on cell migration in SW620 and HT29 cells

To demonstrate the role of CRIP1 in regulating colon cancer cell migration, transwell and wound-healing assays were performed in triplicate after transfection with the CRIP1 siRNA or NC siRNA. In the transwell assay, the number of cells that passed through the membrane into the lower chamber was significantly lower in the CRIP1 siRNA-transfected SW620 and HT29 cells than in the NC siRNA-transfected SW620 and HT29 cells (Fig. 4A and 4B). In the wound-healing assay, the percentage of wound closure was significantly lower in the CRIP1 siRNA-transfected SW620 and HT29 cells than in the NC siRNA-transfected SW620 and HT29 cells (Fig. 4C and 4D).

The effect of CRIP1 silencing on cell invasion in SW620 and HT29 cells

To demonstrate the role of CRIP1 in regulating colon cancer cell invasion, transwell assays were performed in triplicate after transfection with the CRIP1 siRNA or NC siRNA. The 


\section{Cellular Physiology Cell Physiol Biochem 2017;44:897-906 \begin{tabular}{l|l} 
DOI: 10.1159/000485357 & $\begin{array}{l}\text { O } 2017 \text { The Author(s). Published by S. Karger AG, Basel } \\
\text { www.karger.com/cpb }\end{array}$
\end{tabular}

Fig. 5. The effect of cysteine-rich intestinal protein 1 (CRIP1) silencing on cell invasion in SW620 and HT29 cells. SW620 and HT29 cells were transfected with CRIP1 short interfering RNA (siRNA) or scrambled control (NC siRNA), and subsequently cultivated for $24 \mathrm{~h}$. The cells were then placed in the upper chamber of an insert and Matrigel-transwell assays were performed to detect the cell invasion ability of SW620 (A) and HT29 (B). Representative graphs for

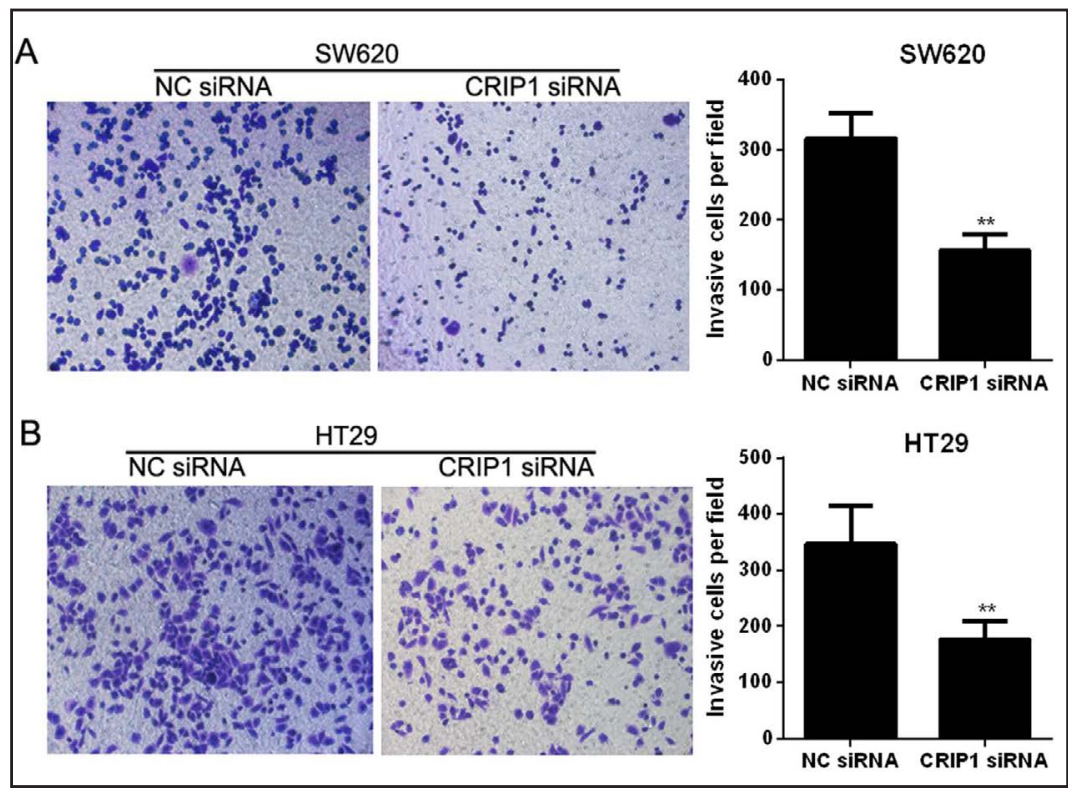
each group are presented on the left. The graphs on the right show the results of analysis of five randomly selected fields. ${ }^{* *} \mathrm{P}<0.01$ compared with NC.Table 1. Correlations between cysteine-rich intestinal protein 1 (CRIP1) protein expression and clinicopathological factors of patients with colorectal cancer.

results showed that the number of cells that passed through the Matrigel-coated membrane into the lower chamber was significantly lower in the CRIP1 siRNA-transfected SW620 and HT29 cells than in the NC siRNA-transfected SW620 and HT29 cells (Fig. 5A and 5B).

\section{Discussion}

The development of CRC is a progressive process comprising genetic changes in tumoursuppressor genes and oncogenes $[15,16]$. Many genetic alterations have been reported to be associated with the development of CRC. Although abnormal CRIP1 expression has been observed in several cancer types, its role in cellular processes, particularly in CRC, remains unclear. In the present study, we found that CRIP1 is overexpressed in metastatic CRC tissues and in two highly metastatic colon cancer cell lines, SW620 and HT29. These results are consistent with a report that CRIP1 is overexpressed in the highly metastatic colon cancer cell line E1 compared with parental HCT-116 cells [13]. In addition, we found that CRIP1 expression was not associated with age, gender or tumour diameter, whereas increased CRIP1 was significantly associated withTNM stage, and lymphatic metastasis. Furthermore, CRIP1 mRNA was abnormally expressed in invasive pancreatic carcinoma and brain and bone-specific breast cancer metastases $[12,17]$. Taken together, these results indicated that CRIP1 expression might be related to the degree of metastasis and is associated with the development of CRC.

To further demonstrate the role of CRIP1 in regulating CRC cell migration and invasion, transwell and wound-healing assays were carried out, which showed that CRIP1 silencing inhibited cell migration and invasion in SW620 and HT29 cells. These results indicated that CRIP1 plays an oncogenic role in CRC progression. However, our results are not consistent with those of a breast cancer study. In T47D and BT474 breast cancer cells, CRIP1 silencing enhanced the invasion of breast cancer cells, indicating that CRIP1 might also act as a tumoursuppressor gene [8]. These results indicated that CRIP1 plays different roles in different cancer types. The function of CRIP1 in regulating cell migration and invasion has only been 
studied in CRC and breast cancer; therefore, further studies are needed to demonstrate the role of CRIP1 in cell lines from other cancers.

Consistent with the functions of other LIM proteins, CRIP appears to be involved in the specific stages of cell proliferation that occur during development and/or after tissue injury and inflammation [18]. For example, CRP1 suppresses cell proliferation and protects against stress-induced cell death in WS1 human skin fibroblasts [19]. In addition, reduced CRIP1 levels might increase cell proliferation and activate cell growth in T47D and BT474 breast cancer cells [8]. However, these observations are not in agreement with our in vitro analyses. After transfection with the CRIP1 siRNA, the $\mathrm{OD}_{490 \mathrm{~nm}}$ showed no obvious change compared to that of cells transfected with NC siRNA, suggesting that low CRIP1 protein levels had no effect on the growth of SW620 and HT29 cells.

Our study has some limitations. First, the function of CRIP1 was studied in only two CRC cell lines, and CRIP1 function should be demonstrated in more CRC cell lines. Second, in vivo studies are needed to confirm the function of CRIP1 in CRC. Finally, the expression of CRIP1 was determined using only 56 CRC tissue samples; thus, more CRC tissue samples are required to confirm the expression patterns and the relationship of CRIP1 levels with prognosis.

In summary, the present study provides evidence that abnormal expression of CRIP1 might be related to the degree of CRC metastasis, and that CRIP1 silencing could effectively inhibit migration and invasion during CRC development. Although further studies are needed to reveal the precise mechanism of CRIP1's involvement in CRC progression, our data reveal a novel molecular basis for the understanding and clinical treatment of CRC.

\section{Disclosure Statement}

The authors declare no conflict of interest.

\section{Acknowledgements}

This study was supported by the Scientific Research Fund of Xinxiang Medical University (No.505124), National Natural Science Foundation of China (Grant No. 81772524) and the Educational Commission of Henan Province, China (No. 18A310023).

\section{References}

1 Torre LA, Bray F, Siegel RL, Ferlay J, Lortet-Tieulent J, Jemal A: Global cancer statistics, 2012. CA Cancer J Clin 2015;65:87-108.

-2 Center MM, Jemal A, Smith RA, Ward E: Worldwide variations in colorectal cancer. CA Cancer J Clin 2009;59:366-378.

-3 Edwards BK, Ward E, Kohler BA, Eheman C, Zauber AG, Anderson RN, Jemal A, Schymura MJ, LansdorpVogelaar I, Seeff LC, van Ballegooijen M, Goede SL, Ries LA: Annual report to the nation on the status of cancer, 1975-2006, featuring colorectal cancer trends and impact of interventions (risk factors, screening, and treatment) to reduce future rates. Cancer 2010;116:544-573.

-4 Sung JJ, Lau JY, Goh KL, Leung WK: Increasing incidence of colorectal cancer in Asia: implications for screening. Lancet Oncol 2005;6:871-876.

5 Gomez del Pulgar T, Bandres E, Espina C, Valdes-Mora F, Perez-Palacios R, Garcia-Amigot F, Garcia-Foncillas J, Lacal JC: Differential expression of Rac1 identifies its target genes and its contribution to progression of colorectal cancer. Int J Biochem Cell Biol 2007;39:2289-2302.

6 Baumhoer D, Elsner M, Smida J, Zillmer S, Rauser S, Schoene C, Balluff B, Bielack S, Jundt G, Walch A, Nathrath M: CRIP1 expression is correlated with a favorable outcome and less metastases in osteosarcoma patients. Oncotarget 2011;2:970-975. 


\section{Cellular Physiology Cell Physiol Biochem 2017;44:897-906 \begin{tabular}{ll|l} 
DOI: 10.1159/000485357 & $\begin{array}{l}\text { O 2017 The Author(s). Published by S. Karger AG, Basel } \\
\text { www.karger.com/cpb }\end{array}$
\end{tabular}}

He et al.: The Function of CRIP1 in Colorectal Cancer

7 Chen Y, Miller C, Mosher R, Zhao X, Deeds J, Morrissey M, Bryant B, Yang D, Meyer R, Cronin F, Gostout BS, Smith-McCune K, Schlegel R: Identification of cervical cancer markers by cDNA and tissue microarrays. Cancer Res 2003;63:1927-1935.

-8 Ludyga N, Englert S, Pflieger K, Rauser S, Braselmann H, Walch A, Auer G, Hofler H, Aubele M: The impact of cysteine-rich intestinal protein 1 (CRIP1) in human breast cancer. Mol Cancer 2013;12:28.

-9 Ma XJ, Salunga R, Tuggle JT, Gaudet J, Enright E, McQuary P, Payette T, Pistone M, Stecker K, Zhang BM, Zhou YX, Varnholt H, Smith B, Gadd M, Chatfield E, Kessler J, Baer TM, Erlander MG, Sgroi DC: Gene expression profiles of human breast cancer progression. Proc Natl Acad Sci U S A 2003;100:5974-5979.

-10 Wang Q, Williamson M, Bott S, Brookman-Amissah N, Freeman A, Nariculam J, Hubank MJ, Ahmed A, Masters JR: Hypomethylation of WNT5A, CRIP1 and S100P in prostate cancer. Oncogene 2007;26:65606565.

11 Balluff B, Rauser S, Meding S, Elsner M, Schone C, Feuchtinger A, Schuhmacher C, Novotny A, Jutting U, Maccarrone G, Sarioglu H, Ueffing M, Braselmann H, Zitzelsberger H, Schmid RM, Hofler H, Ebert MP, Walch A: MALDI imaging identifies prognostic seven-protein signature of novel tissue markers in intestinal-type gastric cancer. Am J Pathol 2011;179:2720-2729.

12 Terris B, Blaveri E, Crnogorac-Jurcevic T, Jones M, Missiaglia E, Ruszniewski P, Sauvanet A, Lemoine NR: Characterization of gene expression profiles in intraductal papillary-mucinous tumors of the pancreas. Am J Pathol 2002;160:1745-1754.

13 Lin Q, Tan HT, Lim TK, Khoo A, Lim KH, Chung MC: iTRAQ analysis of colorectal cancer cell lines suggests Drebrin (DBN1) is overexpressed during liver metastasis. Proteomics 2014;14:1434-1443.

14 Liu XB, Sun AJ, Wang C, Chen LR: [Expression of BRG1 and BRM proteins in prostatic cancer]. Zhonghua Bing Li Xue Za Zhi 2010;39:591-594.

15 Magnetto S, Boissier S, Delmas PD, Clezardin P: Additive antitumor activities of taxoids in combination with the bisphosphonate ibandronate against invasion and adhesion of human breast carcinoma cells to bone. Int J Cancer 1999;83:263-269.

16 Ural AU, Avcu F, Baran Y: Bisphosphonate treatment and radiotherapy in metastatic breast cancer. Med Oncol 2008;25:350-355.

-17 Klein A, Olendrowitz C, Schmutzler R, Hampl J, Schlag PM, Maass N, Arnold N, Wessel R, Ramser J, Meindl A, Scherneck S, Seitz S: Identification of brain- and bone-specific breast cancer metastasis genes. Cancer Lett 2009;276:212-220.

18 Khoo C, Blanchard RK, Sullivan VK, Cousins RJ: Human cysteine-rich intestinal protein: cDNA cloning and expression of recombinant protein and identification in human peripheral blood mononuclear cells. Protein Expr Purif 1997;9:379-387.

19 Latonen L, Jarvinen PM, Laiho M: Cytoskeleton-interacting LIM-domain protein CRP1 suppresses cell proliferation and protects from stress-induced cell death. Exp Cell Res 2008;314:738-747. 